\title{
Formulation and Characterization of Amisulpride Microemulsions for Brain Targeting via Intranasal Route-Pharmacodynamic Evaluation in Rat Model
}

\author{
Abilash Teja Ganta, Ravikrishna Velupula, Krishnaveni Janapareddi* \\ Department of Pharmaceutics, University College of Pharmaceutical Sciences, Warangal, Telangana, INDIA.
}

\begin{abstract}
Amisulpride is an atypical antipsychotic drug with dopamine $\left(D_{2} / D_{3}\right)$ receptor blocker activity. The oral bioavailability of amisulpride was below $48 \%$ due to first pass metabolism and poor aqueous solubility. In order to improve bioavailability and targeting to brain, amisulpride microemulsions for intranasal delivery were developed and evaluated. The amisulpride microemulsions were prepared by water titration method and optimized. The optimized formulation ME10 was composed of $5 \%$ Oleic acid, $65 \%$ of Smix (Tween 80 and PEG 400 in 2:1 ratio) and $30 \%$ of water and showed mean globule size of $117.6 \mathrm{~nm}, \mathrm{PDI} 0.259$, zeta potential $-23.8 \mathrm{mV}$, steady state flux of $217.16 \mu \mathrm{g} / \mathrm{cm}^{2} / \mathrm{hr}$ and was selected as optimized formulation. The influence of Chitosan on permeability was studied and formulation MME1 containing $0.1 \%$ Chitosan showed mean zeta size of $112.5 \mathrm{~nm}$, PDI 0.210 , zeta potential $+15.2 \mathrm{mV}$, pH 6.1 , steady state flux of $245.77 \mu \mathrm{g} / \mathrm{cm}^{2} / \mathrm{hr}$. The steady state flux of optimized formulation MME1 was 1.17 times of ME 10 formulation and 3.88 times of Drug solution. The optimized formulation MME1 did not showed significant toxicity in histopathological evaluation on porcine nasal mucosa treated for $1 \mathrm{hr}$. Locomotor activity was evaluated on psychosis induced male Wistar rats using +MK-801 by Photoactometer.
\end{abstract}

The antipsychotic activity of MME1 treated group was $93.85 \%$, nasal drug solution treated group was $65.07 \%$ and in oral drug Solution treated group was $41.47 \%$ measured in terms of reduction of counts in comparison to positive control. The intranasal MME1 showed significantly high efficiency $(P<0.001)$ Compared to ME nasal and DS oral. Therefore intranasal administration of Amisulpride in microemulsion form could be of potential benefit compared to oral route.

Key words: Amisulpride, Brain targeting, Chitosan, Intranasal delivery, Microemulsion, Schizophrenia.

Correspondence

Dr. Krishnaveni Janapareddi,

Department of Pharmaceutics, University College of Pharmaceutical Sciences, Warangal-506009, Telangana, INDIA.

Phone: +919247161127

Email: krishnaveni.janapareddi@gmail.com

DOI: 10.5530/jyp.2020.12s.42

\section{INTRODUCTION}

Schizophrenia is a neurological disorder characterized by increased levels of dopamine in brain. It is a chronic and severe mental disorder that affects how a person thinks, feels and behaves, People with schizophrenia may seem like they have lost touch with reality. It is treated with both typical and atypical anti-psychotic drugs. Amisulpride is an atypical anti-psychotic drug with D2/D3 receptor blocker activity and effective in both positive and negative symptoms of schizophrenia. The limitation in oral bioavailability of amisulpride was due to poor aqueous solubility and first pass metabolism. ${ }^{1,2}$ For higher dug absorption and to increase drug concentration in brain, nasal route is preferred hence selected for the studies. Blood-brain barrier and cerebrospinal fluid barrier are the major obstacles that limit delivery of drugs to brain, which is avoided in nasal route. ${ }^{3,4,5}$

Intra-nasal therapy has been recognized form of treatment in the Ayurveda system of Indian medicine. It is known as 'Nasya Karma', one of the panchakarma of Ayurveda. ${ }^{6}$ It has been given a new lease of life. It's a useful delivery method for drugs that are active in low doses and show no or minimal oral bioavailability such as proteins and peptides. Nasal mucosa has been considered as a potential administration route to achieve faster and higher level of drug absorption, due to rich vasculature of nasal mucosa, ${ }^{7,8}$ Degradation of drug due to $\mathrm{pH}$, metabolizing enzymes is negligible when compared to GIT. Hepatic first pass metabolism can be avoided.
Olfactory region (smelling area in nose) and trigeminal nerve pathways of nasal mucosa that provide a direct connection between nose and brain is used for treatment of CNS disorders. ${ }^{9-12}$

Microemulsions are colloidal dispersions composed of oil phase, aqueous phase, surfactant and co surfactant at appropriate ratios. Itis optically isotropic and thermodynamically stable liquid solution.Microemulsions have good solubilizing capacity and could be employed as an effective carrier for the poorly soluble drugs. Also due to the nano sized globules, the absorption of micro emulsion is higher than simple solution. Hence microemulsions were selected for the present study. ${ }^{13-17}$

\section{MATERIALS AND METHODS}

\section{Materials}

Amisulpride was gifted by Dr. Reddy's (Hyderabad, India). Labrasol, Transcutol P, lauroglycol 90, capmul MCM were received as gift samples from Gattefosse Company (Mumbai, India). Polyethylene glycol 400 (PEG 400), Polysorbate 80, Oleic acid, coconut oil, Tween 20, Propylene glycol, potassium chloride, Oleic acid, Arachis oil, sodium hydroxide, potassium dihydrogen orthophosphate, potassium chloride were purchased from SD fine chem Ltd (Mumbai, India) are of analytical grade. Methanol and Acetonitrile were purchased from Merck Limited (Mumbai, India). All other chemicals were analytical grade and purchased commercially. Double distilled water was used throughout the study. 


\section{Solubility}

$2 \mathrm{ml}$ of each of the selected vehicle was taken in glass vial to which excess of Amisulpride was added. They were mixed using a cyclomixer to facilitate uniform dispersion. Then the mixtures were agitated in a shaker at room temperature. Samples were collected at $48 \mathrm{hrs}$ intervals, centrifuged at $400 \mathrm{rpm}$ for $10 \mathrm{~min}$ and filtrated through $0.45 \mu \mathrm{m}$ membrane filter. The concentration of drug was quantified by U.V. visible spectrophotometer. ${ }^{18,19}$

\section{Construction of Pseudo Ternary Phase Diagram}

Phase diagrams were constructed using CHEMIX software version 7.00. Plots were constructed at different ratios of surfactant mixture (Smix) $1: 9,2: 1,3: 1,2: 1$,). The weight ratio of oil to surfactant mixture (Smix) was varied as 1:9, 2:8, 3:7, 4:6, 5:5, 6:7, 7:3, 8:2 and 9:1. To the homogenous mixture of oil and surfactant, water was added incrementally. Following each addition, the mixture in test tube was vortexed for 2-3 mins. the point at which the mixture becomes turbid was considered as the end point of titration and recorded. They were allowed to settle for $30 \mathrm{~min}$. The mixture was examined visually for phase separation or transparency. If transparent, water was added further till it becomes turbid and quantity of water was noted. ${ }^{13,18,19}$

\section{Preparation Methods \\ Microemulsions}

Microemulsions were prepared by water titration method. Accurately weighed amount of drug was dissolved in weighed quantities of oil, Smix by vortexing. Measured volume of distilled water was added dropwise to the above mixture and vortexed to obtain transparent microemulsion. ${ }^{20,21}$ The composition of microemulsions was showed in Table 1.

\section{Mucoadhesive Microemulsions}

Mucoadhesive microemulsions were prepared by adding chitosan dissolved in $1 \%$ acetic acid to microemulsion formulation with intermittent mixing. $22-25$

\section{Characterization \\ Transmittance}

The percentage transmittance of the ME and MME was measured against distilled water using UV-Visible spectrophotometer at a wave length of $633 \mathrm{~nm}^{19}$

\section{Mean Globule Size, PDI}

The mean globule size and PDI of MEs and MMEs were determined using Zeta sizer (Nano-ZS 90, Malvern instruments Ltd. UK) on 100 times diluted sample. The mean globule size was measured at $90^{\circ} \mathrm{C}$ angle at room temperature. ${ }^{26,27}$

\section{Zeta Potential}

Zeta potential of MEs, MMEs were determined using zeta sizer (Nano-ZS 90, Malvern instruments Ltd. UK) on 100 time's diluted sample. The zeta potential was measured at $90^{\circ}$ angle at room temperature..$^{26,27}$

\section{$\mathrm{pH}$ and Viscosity}

The $\mathrm{pH}$ of microemulsion formulations was determined using calibrated digital $\mathrm{pH}$ meter at room temperature. Viscosity of $\mathrm{ME}$ and MME were determined using Brookfield viscometer (Brookfield, model No. LVDV-E 8542328, USA) at single mode (spindle C-50). ${ }^{28}$

\section{Drug Content}

Accurately weighed microemulsions were suitably diluted with methanol, sonicated, filtered through $0.45 \mu \mathrm{m}$ filter and analysed by HPLC method. ${ }^{29}$

\section{In vitro Drug Permeation Study of Microemulsions}

Invitro drug permeation studies were assessed using Franz diffusion cell. Microemulsion formulation equivalent to $12.5 \mathrm{mg}$ of Amisulpride was placed in donor compartment separated from receptor compartment by a dialysis membrane of 12000 - 14000 Daltons pore size cut off. Aliquots of samples were withdrawn from the receptor compartment at predetermined time intervals and replaced with fresh medium. The samples were analysed for drug content by UV-Visible spectrophotometer at $224 \mathrm{~nm} .{ }^{30}$

\section{Ex vivo Permeation Studies}

\section{Procedure for Isolation of Nasal Mucosa}

On the day of experiment, the isolated nose of porcine was collected from local slaughter house and kept in Krebs bicarbonate ringer's solution, immediately after slaughtering. The nasal mucosa was isolated carefully using scalpel blade, blunt forceps made free from adhered tissues and used immediately. ${ }^{31}$

\section{Ex vivo Permeation Studies}

Exvivo permeation were performed on excised porcine nasal mucosa using Franz diffusion cells of vertical type (volume $23 \mathrm{~mL}$ ), with effective surface area of $4.9 \mathrm{~cm}^{2}$. The isolated porcine nasal mucosa was mounted on Franz diffusion cells and allowed to equilibrate for 30 min in PBS $\mathrm{pH} 6.4$ at room temperature. After equilibrium the donor chamber was replaced with formulation/drug solution and the receptor compartment was filled with fresh medium. Samples were withdrawn at regular intervals up to $8 \mathrm{hr}$ and replaced with fresh medium. The samples were analysed by UV visible spectrophotometer at $224 \mathrm{~nm}^{31}$

\section{Nasal Cilio Toxicity Studies}

Nasal mucosae mounted on Franz diffusion cell was treated individually for $1 \mathrm{~h}$ with formulations, isopropyl alcohol (positive control) and PBS 6.4 (negative control). The mucosae after treatment was rinsed with PBS $\mathrm{pH} 6.4$ and preserved in $10 \% \mathrm{v} / \mathrm{v}$ formalin solution. The mucosal section obtained by microtome technique was stained with haematoxylin-eosin and observed under digital microscope to evaluate the damage to nasal mucosa. ${ }^{19}$

\section{Scanning Electron Microscopy (SEM)}

The morphology of optimized mucoadhesive microemulsion was studied by scanning electron microscope (JSM-6510LA, JEOL, Indonesia). The sample of microemulsion formulation was adhered on to the carboncoated metallic stub, sputter coated with platinum coating machine (JFC1600 Auto coater, JEOL). Image was taken out under high vacuum. ${ }^{32}$

\section{Stability Studies}

Freeze thawing was employed to evaluate the physical stability of the optimal formulations. The formulations in glass vials were subjected to freeze-thaw cycles, which include freezing at $-20^{\circ} \mathrm{C}$ for $24 \mathrm{hr}$ followed by thawing at $40^{\circ} \mathrm{C}$ for $24 \mathrm{hr}$. After completion of freeze-thaw cycles, samples were centrifuged at $3000 \mathrm{rpm}$ for $5 \mathrm{~min}$ and observed for phase separation and precipitation of drug. ${ }^{19}$

Optimized microemulsion and mucoadhesive microemulsion were subjected to sterilization in an autoclave at $121^{\circ} \mathrm{C}$ for $15 \mathrm{~min}$ and observed for phase separation and precipitation of drug. 


\section{DSC Thermogram}

Equal ratios of formulation and neusilin as adsorbent taken in chaina dish were triturated well. About $15 \mathrm{mg}$ of triturate was weighed into aluminium pan and crimped after placing the lid. The sample was scanned between the temperature range of $50-400^{\circ} \mathrm{C}$ at a heating rate of $10 \mathrm{C} / \mathrm{min}$. Nitrogen gas was served as purged gas. Empty aluminium pan was used as reference cell (DSC-800, Perkin Elmer, USA). ${ }^{19,31}$

\section{In vivo Studies}

\section{Animals}

Male Wister rats weighing between 200-250 gm were used in Pharmacodynamic studies. All experiments were conducted as per CPCSEA guidelines and approved by institutional animal ethical committee, Kakatiya University, Warangal vide No IAEC/32/UCPSc/ $\mathrm{KU} / 2019$.

\section{Procedure for Intranasal Administration}

Rat intranasal catheter device (ICD) is specially designed to deliver therapeutics to the olfactory region of the rat nasal cavity. It consists of catheter guide, catheter tube, base and Hamilton syringe. Catheter tube passes through catheter guide, which is slightly bent such that the tube can be guided on to the olfactory bulb. The Hamilton syringe filled with dose, is kept ready by attaching to the other end of the catheter tube. After ensuring the proper positioning of the tube, the dose is pushed into the nose. Rat nasal catheter device (Impel Neuro Pharma, version 2.1) was used for the intranasal administration of formulations. The formulations were administered to anaesthetized rats. ${ }^{19,33}$

\section{Study Protocol}

Male Wistar rats weighing between 200-250 g were divided into six groups; each group consists of 6 rats. The dose and route of administration was mentioned in the Table $6 .{ }^{19,33}$

\section{Description of the Procedure}

Photoactometer is used to evaluate antipsychotic activity. First the amisulpride dose was given through the respective routes mentioned in Table 6. After $30 \mathrm{~min}$ of treatment MK-801 was administered via intraperitoneal route to all rats except group 1 rats. The rats were placed in photoactometer and the movement of rats passing in counts were recorded at 15, 30, 45, $90 \mathrm{~min}$ and compared to positive control.

\section{RESULTS AND DISCUSSION}

\section{Solubility}

The solubility of amisulpride in various oils, surfactants and co-surfactants and various buffers was shown in the Figure 1. Based on solubility of

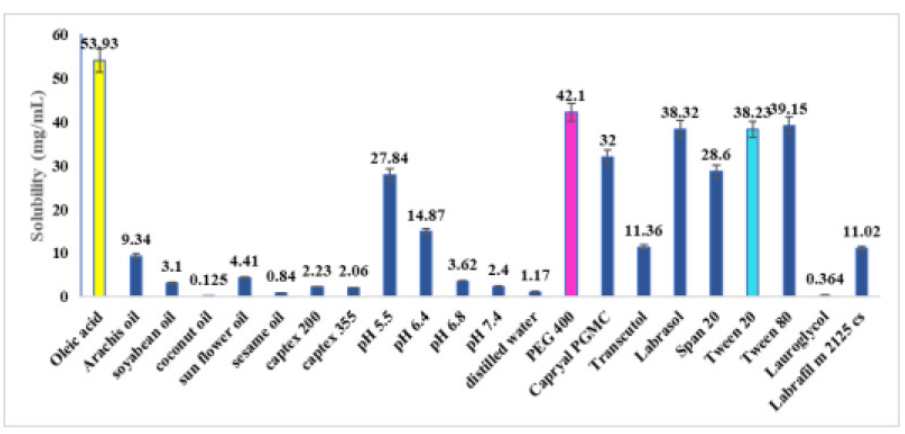

Figure 1: Solubility of amisulpride in various oils, surfactants, co-surfactants and in various buffers.

\begin{tabular}{ccccc}
\multicolumn{6}{l}{ Table 1: Microemulsion formulations. } \\
\hline S.no & Formulation code & Oil (\%) & Smix (\%) & Water (\%) \\
\hline 1 & ME 1 & 15 & 65 & 20 \\
2 & ME 2 & 15 & 62.5 & 22.5 \\
3 & ME 3 & 15 & 60 & 25 \\
4 & ME 4 & 15 & 57.5 & 27.5 \\
5 & ME 5 & 12.5 & 65 & 22.5 \\
6 & ME 6 & 12.5 & 62.5 & 25 \\
7 & ME 7 & 12.5 & 60 & 27.5 \\
8 & ME 8 & 7.5 & 65 & 27.5 \\
9 & ME 9 & 7.5 & 62.5 & 30.5 \\
10 & ME 10 & 5 & 65 & 30 \\
\hline
\end{tabular}

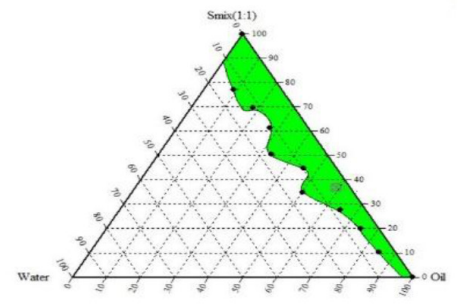

a) $\operatorname{Smix}(1: 1)$

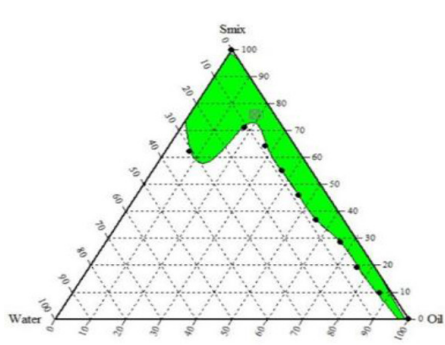

c) $\operatorname{Smix}(3: 1)$

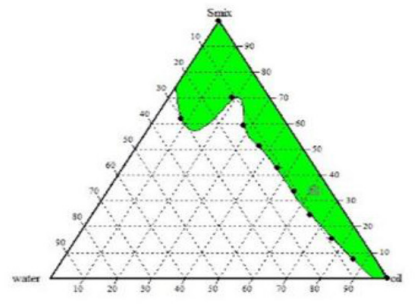

b) $\operatorname{Smix}(2: 1)$

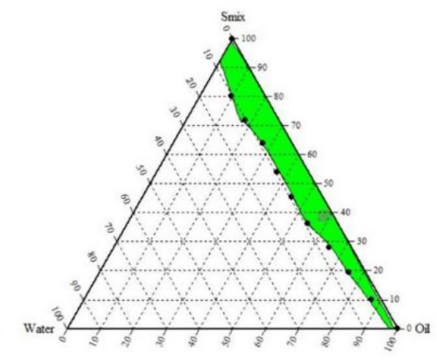

d) $\operatorname{Smix}(1: 2)$
Figure 2 (a, b, c, d): Pseudo ternary phase diagrams composed of oil (oleic acid) Smix (Tween 80: PEG 400 and water. Shaded area represents microemulsion region.

amisulpride, Oleic acid, Tween 80 and PEG 400 were selected as oil, surfactant and co-surfactant.

\section{Pseudo Ternary Phase Diagrams}

Pseudo ternary phase diagrams drawn with different ratios of tween 80: PEG 400 (1:1, 2:1, 3:1, 1:2) (surfactant and co-surfactant) were shown in Figure 2. Tween 80 and PEG 400 Smix at 2:1 ratio, Figure 2(b) yielded maximum microemulsion region. Hence 2:1 ratio of Tween 80 and PEG 400 was selected for microemulsion formulations. Tween 80 is a biocompatible emulsifier. PEG 400 is a stabilizer and cosurfactant which imparts flexibility to the surface of the globules.

\section{Characterization}

The microemulsions and mucoadhesive microemulsions were characterized for globule size, PDI, zeta potential, $\mathrm{pH}$, drug content as per the procedure described above and the results were shown in Table's 2 and 3. 
Table 2: Characterization of microemulsions.

\begin{tabular}{|c|c|c|c|c|c|c|c|}
\hline Formulation code & Drug content $(\%) \pm S D$ & Size $(n m) \pm S D$ & $\mathrm{PDI} \pm \mathrm{SD}$ & $\mathrm{ZP}(\mathrm{mv}) \pm \mathrm{SD}$ & $\mathrm{pH}$ & Transmittance $\%$ & $\mathrm{Kp} \cdot 10^{-3} \mathrm{~cm}^{2} / \mathrm{h}$ \\
\hline ME 1 & $97.42 \pm 1.9$ & $179 \pm 3.95$ & $0.228 \pm 0.02$ & $32.70 \pm 1.21$ & 5.3 & 99.2 & 11.39 \\
\hline ME 2 & $95.6 \pm 1.43$ & $192.0 \pm 3.95$ & $0.258 \pm 0.02$ & $-31.06 \pm 0.56$ & 5.2 & 99 & 8.53 \\
\hline ME 3 & $96.3 \pm 1.39$ & $198.0 \pm 4.58$ & $0.271 \pm 0.05$ & $-31.53 \pm 1.00$ & 5.5 & 98.2 & 8.05 \\
\hline ME 4 & $96.4 \pm 1.98$ & $319.9 \pm 5.1$ & $0.390 \pm 0.08$ & $-31.73 \pm 0.47$ & 5.6 & 98 & - \\
\hline ME 5 & $97.1 \pm 1.56$ & 155. \pm 10.3 & $0.230 \pm 0.01$ & $-29.66 \pm 1.34$ & 5.2 & 97.09 & 11.73 \\
\hline ME 6 & $98.2 \pm 1.72$ & $159.8 \pm 7.08$ & $0.227 \pm 0.02$ & $-27.53 \pm 0.55$ & 5.7 & 97.06 & 10.38 \\
\hline ME 7 & $96.5 \pm 1.92$ & $170.4 \pm 4.88$ & $0.252 \pm 0.03$ & $-24.30 \pm 2.06$ & 5.4 & 99.03 & 9.33 \\
\hline ME 8 & $96.1 \pm 1.08$ & $134.2 \pm 5.29$ & $0.279 \pm 0.02$ & $-25.40 \pm 0.50$ & 5.3 & 98.2 & 15.92 \\
\hline ME 9 & $95.7 \pm 1.75$ & $148.6 \pm 9.50$ & $0.263 \pm 0.01$ & -25.360 .40 & 5.7 & 96.2 & 14.08 \\
\hline ME 10 & $95.2 \pm 1.87$ & $117.6 \pm 7.37$ & $0.259 \pm 0.05$ & $-23.83 \pm 1.16$ & 5.7 & 99.2 & 16.78 \\
\hline
\end{tabular}

mean $\pm S D ; n=3$

Table 3: Characterization of optimized microemulsions, mucoadhesive microemulsions and drug solution.

\begin{tabular}{|c|c|c|c|c|c|c|}
\hline Formulation code & Size $(n m)$ & PDI & Zeta potential (mV) & Drug content (\%) & $\mathrm{pH}$ & $\mathrm{Kp} \cdot 10^{-3} \mathrm{~cm}^{2} / \mathrm{h}$ ) \\
\hline ME 8 & $134.0 \pm 5.29$ & $0.279 \pm 0.02$ & $-25.40 \pm 0.50$ & $96.1 \pm 1.08$ & 5.3 & 15.58 \\
\hline ME 9 & $148.6 \pm 9.50$ & $0.263 \pm 0.01$ & $-25.36 \pm 0.40$ & $95.7 \pm 1.75$ & 5.7 & 12.86 \\
\hline ME 10 & $117.6 \pm 7.37$ & $0.259 \pm 0.05$ & $-23.83 \pm 1.16$ & $95.6 \pm 1.12$ & 5.7 & 17.37 \\
\hline MME 1 & $112.6 \pm 7.37$ & $0.210 \pm 0.03$ & $+15.2 \pm 2.02$ & $95.6 \pm 1.12$ & 6.1 & 19.66 \\
\hline MME 2 & $115.9 \pm 8.5$ & $0.275 \pm 0.08$ & $+23.3 \pm 2.01$ & $96.7 \pm 1.87$ & 6.4 & 20.50 \\
\hline MME 3 & 115.98 .5 & 0.2980 .05 & $+27.5 \pm 2.05$ & $95.8 \pm 1.56$ & 6.7 & 15.81 \\
\hline Drug solution & - & - & - & $95.4 \pm 1.89$ & 6.1 & 5.06 \\
\hline
\end{tabular}

mean \pm SD; $n=3$

Table 4: Cumulative amount $(\mathrm{mg})$ of amisulpride permeated through dialysis membrane(mean $\pm \mathrm{SD}, n=3$ ).

\begin{tabular}{cccccccccc}
\hline Time(hrs) & ME 1 & ME 2 & ME 3 & ME 5 & ME 6 & ME 7 & ME 8 & ME 9 & ME 10 \\
\hline 0.08 & $0.13 \pm 0.09$ & $0.08 \pm 0.01$ & $0.05 \pm 0.01$ & $0.01 \pm 0.0$ & $0.01 \pm 0.0$ & $0.09 \pm 0.0$ & $0.20 \pm 0.00$ & $0.20 \pm 0.07$ & $0.15 \pm 0.01$ \\
0.25 & $0.45 \pm 0.11$ & $0.36 \pm 0.08$ & $0.25 \pm 0.07$ & $0.41 \pm 0.09$ & $0.28 \pm 0.09$ & $0.42 \pm 0.08$ & $0.44 \pm 0.08$ & $0.38 \pm 0.09$ & $0.43 \pm 0.03$ \\
0.5 & $0.62 \pm 0.11$ & $0.45 \pm 0.1$ & $0.43 \pm 0.1$ & $0.50 \pm 0.08$ & $0.36 \pm 0.03$ & $0.52 \pm 0.07$ & $0.57 \pm 0.09$ & $0.47 \pm 0.08$ & $0.52 \pm 0.02$ \\
1 & $0.99 \pm 0.10$ & $0.68 \pm 0.08$ & $0.66 \pm 0.06$ & $1.01 \pm 0.08$ & $0.97 \pm 0.08$ & $0.73 \pm 0.06$ & $1.10 \pm 0.07$ & $0.96 \pm 0.09$ & $1.02 \pm 0.08$ \\
2 & $1.25 \pm 0.9$ & $1.29 \pm 0.1$ & $1.26 \pm 0.08$ & $1.37 \pm 0.09$ & $1.49 \pm 0.05$ & $1.35 \pm 0.09$ & $2.26 \pm 0.09$ & $1.92 \pm 0.03$ & $2.30 \pm 0.07$ \\
3 & $1.51 \pm 0.9$ & $1.92 \pm 0.10$ & $1.85 \pm 0.09$ & $2.0 \pm 0.09$ & $2.28 \pm 0.09$ & $2.00 \pm 0.98$ & $3.14 \pm 0.078$ & $3.62 \pm 0.07$ & $4.25 \pm 0.12$ \\
4 & $1.79 \pm 0.1$ & $2.68 \pm 0.8$ & $2.49 \pm 0.1$ & $2.96 \pm 0.10$ & $3.41 \pm 0.72$ & $2.94 \pm 0.08$ & $4.28 \pm 0.09$ & $5.13 \pm 0.10$ & $5.25 \pm 0.10$ \\
6 & $2.23 \pm 0.1$ & $3.26 \pm 0.9$ & $3.38 \pm 0.10$ & $4.16 \pm 0.12$ & $4.07 \pm 0.10$ & $3.71 \pm 0.92$ & $5.42 \pm 0.12$ & $6.23 \pm 0.09$ & $6.63 \pm 0.09$ \\
8 & $2.92 \pm 0.9$ & $4.13 \pm 0.1$ & $3.77 \pm 0.11$ & $5.80 \pm 0.12$ & $4.98 \pm 0.12$ & $4.46 \pm 0.11$ & $6.71 \pm 0.11$ & $7.51 \pm 0.11$ & $7.87 \pm 0.13$ \\
\hline
\end{tabular}

\section{Transmittance}

All the formulations were transparent when measured at $693 \mathrm{~nm}$ by UV spectrophotometer, indicating the nano sized globules of ME.

\section{Size, PDI}

The mean globule size of design microemulsion formulations was in the range of $112.6 \mathrm{~nm}$ to $319.9 \mathrm{~nm}$. Table 2. The globule size of optimized microemulsion was $117.6 \mathrm{~nm}$. The PDI of the design formulations was in the range of 0.210 to 0.390 indicating uniform dispersion of globules. The globule size of optimized mucoadhesive microemulsion MME 1 was $112.6 \mathrm{~nm}$ with PDI of \pm 0.210 . Table 2 .

\section{Zeta Potential}

The zeta potential is a key factor for the stability of the colloidal dispersion. Zeta potential of the MEs were observed as negative value. Table 2. The high zeta potential of the ME was because of the presence of oleic acid. Oleic acid is a long chain fatty acid, ionization of oleic acid imparts high negativity charge. The zeta potential of MME were observed as positive value due to the presence of chitosan.

\section{Measurement of $\mathrm{pH}$}

The $\mathrm{pH}$ of the design formulations was found to be within the range of 5.2 to 6.7. The $\mathrm{pH}$ of the optimized microemulsion was 5.7. The $\mathrm{pH}$ of the optimized MME 1 was 6.1. In general the $\mathrm{pH}$ of nasal secretions is between 4.5 and 6.4. As the optimized formulation was within the range of nasal secretions, formulations could be non-irritant to the nasal mucosa. 


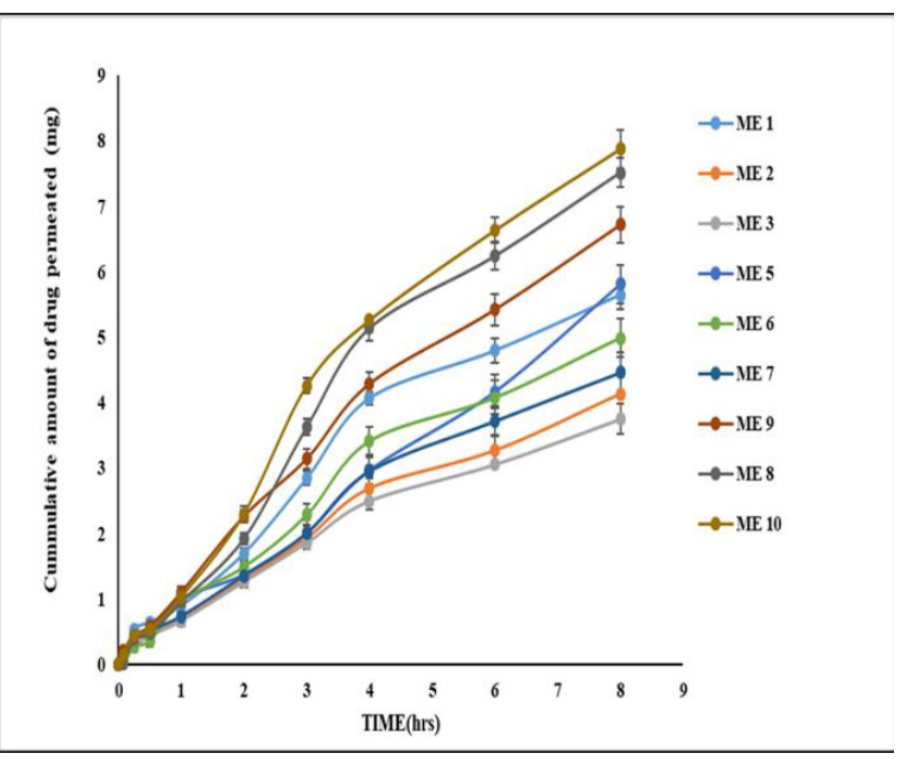

Figure 3: In vitro permeation profiles of Amisulpride microemulsions ME, $M M E$, drug solution.

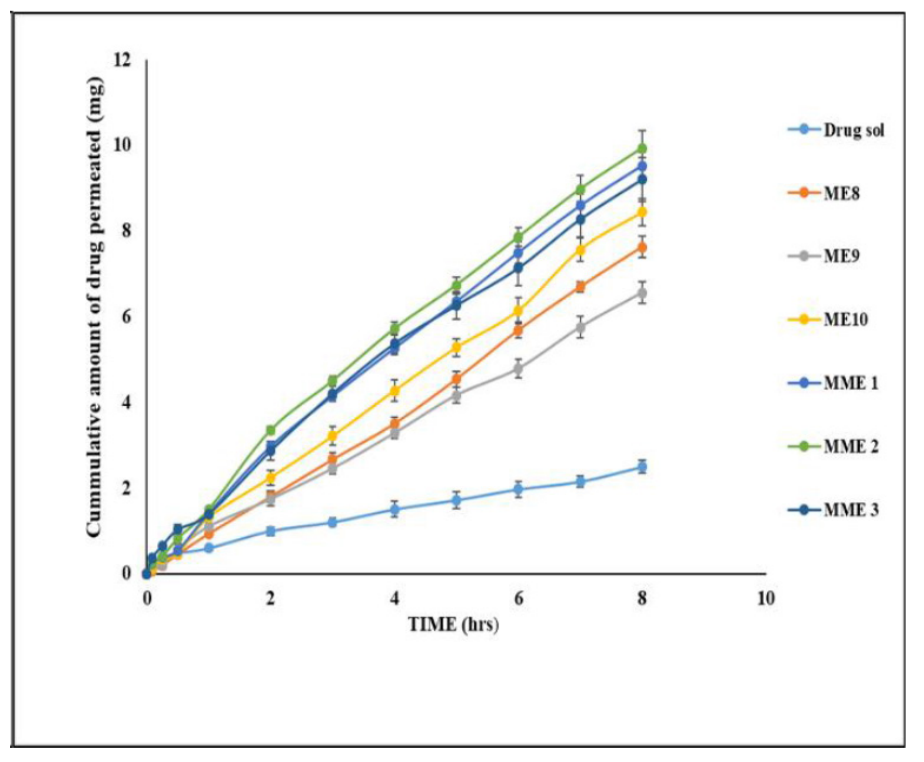

Figure 4: Ex vivo permeation profiles of Amisulpride microemulsions $M E$, $M M E$, drug solution.

Table 5: Cumulative amount $(\mathrm{mg})$ of amisulpride permeated through nasal mucosa (mean $\pm S D, n=3$ ).

\begin{tabular}{|c|c|c|c|c|c|c|c|}
\hline Time & ME 8 & ME 9 & ME 10 & MME 1 & MME 2 & MME 3 & Drug solution \\
\hline 0 & 0 & 0 & 0 & 0 & 0 & 0 & 0 \\
\hline 0.083 & $0.06 \pm 0.0$ & $0.10 \pm 0.01$ & $0.12 \pm 0.02$ & $0.23 \pm 0.03$ & $0.26 \pm 0.03$ & $0.36 \pm 0.02$ & $0.18 \pm 0.01$ \\
\hline 0.25 & $0.19 \pm 0.02$ & $0.21 \pm 0.03$ & $0.33 \pm 0.02$ & $0.37 \pm 0.03$ & $0.40 \pm 0.01$ & $0.65 \pm 0.03$ & $0.35 \pm 0.03$ \\
\hline 0.5 & $0.45 \pm 0.07$ & $0.56 \pm 0.09$ & $0.47 \pm 0.09$ & $0.53 \pm 0.06$ & $0.82 \pm 0.01$ & $1.02 \pm 0.09$ & $0.47 \pm 0.09$ \\
\hline 1 & $0.92 \pm 0.02$ & $1.10 \pm 0.08$ & $1.31 \pm 0.02$ & $1.40 \pm 0.08$ & $1.50 \pm 0.09$ & $1.39 \pm 0.7$ & $0.59 \pm 0.08$ \\
\hline 2 & $1.79 \pm 0.09$ & $1.74 \pm 0.10$ & $2.24 \pm 0.09$ & $2.96 \pm 0.10$ & $3.34 \pm 0.08$ & $2.86 \pm 0.98$ & $0.99 \pm 0.07$ \\
\hline 3 & $2.66 \pm 0.09$ & $2.45 \pm 0.12$ & $3.20 \pm 0.08$ & $4.14 \pm 0.13$ & $4.50 \pm 0.12$ & $4.20 \pm 0.12$ & $1.19 \pm 0.09$ \\
\hline 4 & $3.49 \pm 0.11$ & $3.28 \pm 0.09$ & $4.27 \pm 0.09$ & $5.26 \pm 0.12$ & $5.72 \pm 0.15$ & $5.37 \pm 0.14$ & $1.50 \pm 0.10$ \\
\hline 5 & $4.53 \pm 0.12$ & $4.16 \pm 0.13$ & $5.27 \pm 0.10$ & $6.35 \pm 0.11$ & $6.73 \pm 0.11$ & $6.26 \pm 0.11$ & $1.71 \pm 0.10$ \\
\hline 6 & $5.68 \pm 0.09$ & $4.78 \pm 0.11$ & $6.14 \pm 0.12$ & $7.49 \pm 0.16$ & $7.85 \pm 0.19$ & $7.13 \pm 0.17$ & $1.96 \pm 0.0 .09$ \\
\hline 7 & $6.69 \pm 0.10$ & $5.75 \pm 0.12$ & $7.56 \pm 0.15$ & $8.59 \pm 0.13$ & $8.97 \pm 0.16$ & $8.27 \pm 0.19$ & $2.15 \pm 0.11$ \\
\hline 8 & $7.62 \pm 0.9$ & $6.55 \pm 0.13$ & $8.43 \pm 0.12$ & $9.52 \pm 0.18$ & $9.93 \pm 0.18$ & $9.20 \pm 0.12$ & $2.49 \pm 0.10$ \\
\hline
\end{tabular}

\section{Drug Content}

The drug content of all formulations was within the range of $95 \pm 4 \%$. Amisulpride was loaded at $1.2 \%$ concentration of the formulation.

\section{In-vitro Drug Permeation Studies}

In-vitro drug permeation studies were conducted in phosphate buffer saline pH 6.4 using Franz diffusion cells. The release profiles were shown in Table 4. And Figure 3. The formulation with lower size shown higher release, the release pattern is $\mathrm{ME} 10>\mathrm{ME} 8>\mathrm{ME} 9>\mathrm{ME} 5>\mathrm{ME} 6>\mathrm{ME}$ 7> ME 2> ME 3> ME 1. The ME 10, ME 9, ME 8 formulations showed highest drug permeated (70.26\%) in 8 hrs. Hence selected for further invivo studies.

\section{Ex vivo Drug Permeation Studies}

The ex vivo permeation studies were conducted using Franz diffusion cell on porcine nasal mucosa using PBS $\mathrm{pH}$ 6.4. Cumulative amount of drug permeated, Flux at steady state $\left(\mathrm{J}_{\mathrm{ss}}\right), \mathrm{Kp}$, were calculated. The donor compartment was loaded with formulation equivalent to $12.5 \mathrm{mg}$ of drug. The cumulative amount of drug permeated in $8 \mathrm{hr}$ was shown in (Table 5), the permeation profiles were shown in (Figure 4). Flux at steady state was obtained from slope of straight line linear portion. Steady state flux values of design formulations were in between 63.28 and $256.32 \mu \mathrm{g} / \mathrm{cm}^{2} / \mathrm{hr}$. (Figure 6). Optimized microemulsion (ME 10) showed a flux of $217.16 \mu \mathrm{g} / \mathrm{cm}^{2} / \mathrm{hr}$.

Mucoadhesive microemulsions containing chitosan at $0.1,0.3$ and $0.5 \% \mathrm{w} / \mathrm{w}$ showed flux of $245.77,256.32$ and $237.16 \mu \mathrm{g} / \mathrm{cm}^{2} / \mathrm{hr}$ respectively. As MME 1 and MME 2 containing 0.1 and $0.3 \%$ chitosan showed significantly high flux, MME 1 shown high flux and $\mathrm{pH}$ was within the nasal secretions range hence selected for Pharmacodynamic study. Increasing the concentration of chitosan above $0.3 \%$ decreased the flux, which may be due to increase in formulation viscosity.

Flux of MME 1 was significantly high compared to drug solution $(P<0.001)$ and ME $10(P<0.0001)$. The enhancement ratio of MME1 was 3.88 folds when compared to drug solution and 1.17 folds compared to microemulsion (ME 10) 
Permeation coefficients (Kp) of design MEs were in the range of 12.86 to $20.50 \mathrm{~cm}^{-3} / \mathrm{h}$ (Table 4.14). Kp of MME1 was 1.13 folds, when compared to ME 10 and 3.88 folds when compared to drug solution.

Significantly high value of flux and $\mathrm{kp}$ of optimized microemulsion (ME 10) and mucoadhesive microemulsion (MME 1) when compared to drug solution were observed. This results proven the superiority of microemulsion and MME formulation over drug solution. This can be attributed to the nano sized globules present in thermodynamically active microemulsion form. The role of chitosan as permeation enhancer was also proved as MME 1 exhibited maximum flux, significantly high compared to microemulsion.

\section{Nasal Cilio Toxicity Studies}

Nasal cilio toxicity studies were conducted as per the procedure described in section 2.7. Mucosa treated with formulations ME 10, MME

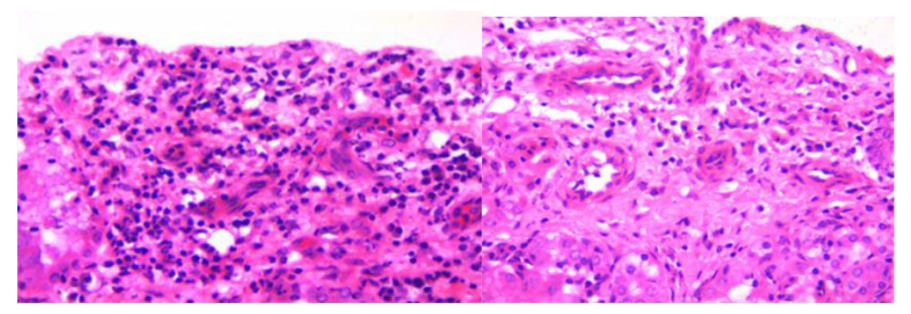

\section{a. Isopropyl alcoholb. PBS pH 5.6}

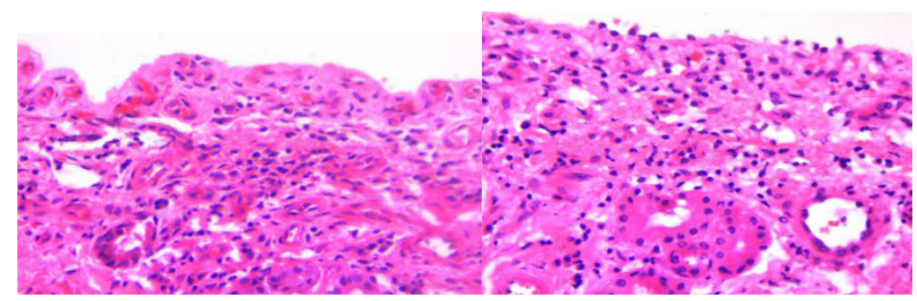

c. ME 10

d. MME 1

Figure 5: $(a, b, c, d)$ : Histopathology of porcine nasal mucosa after treatment formulations.

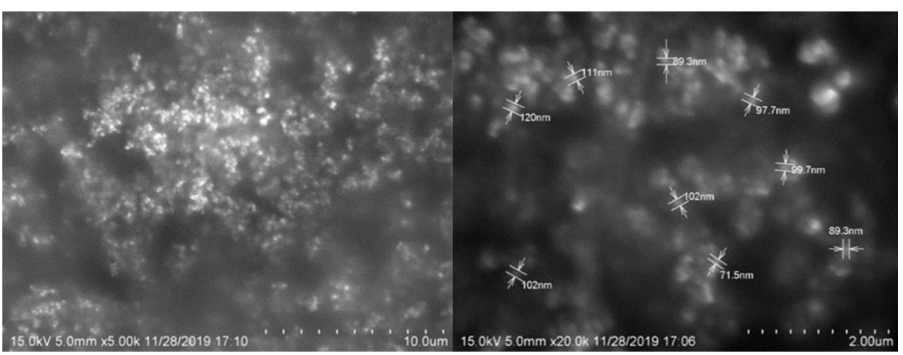

Figure 6: SEM image of optimized Formulations MME.

Table 6: Study protocol of locomotor activity in Male Wistar rats.

\begin{tabular}{cccccc}
\hline Name & $\begin{array}{c}\text { Group-1 (Normal } \\
\text { saline) }\end{array}$ & $\begin{array}{c}\text { Group-2 (positive } \\
\text { control) }\end{array}$ & $\begin{array}{c}\text { Group-3 (Oral Drug } \\
\text { solution) }\end{array}$ & $\begin{array}{c}\text { Group-4 (Nasal Drug } \\
\text { solution) }\end{array}$ & Group-5 (MME1) \\
\hline Amisulpride (mg/kg) & Normal saline (i.p) & --- & 1.2 & 1.2 & 1.2 \\
(NK-801 (mg/kg) & ---- & 0.3 & 0.3 & 0.3 & (Nasal route) \\
\hline
\end{tabular}

1 and PBS pH 6.4 (negative control) did not showed any damaged of the mucosal epithelial layer, cilia and glands. From observation of images in Figure 5 (a, b, c, d,) one can conclude that MME 1 were safe without any significant toxicity.

\section{Scanning Electron Microscopy (SEM)}

Optimized microemulsions and mucoadhesive microemulsions were subjected to SEM studies. The SEM image of mucoadhesive microemulsion formulation contained spherical shaped globules (Figure 6)

\section{Stability Studies}

Physical stability of optimized microemulsion (ME 10), optimized mucoadhesive microemulsion was evaluated and found stable

\section{Physical Stability by Freeze-Thawing}

Optimized microemulsion (ME 10) and optimized mucoadhesive microemulsion (MME 1) formulations were subjected to freeze-thawing for 3 cycles and phase separation was not observed.

\section{Effect of Autoclave}

Before autoclave and after autoclave, phase separation and drug precipitation was not observed in optimized microemulsion and mucoadhesive microemulsion.

\section{DSC Thermogram}

DSC thermogram of optimized formulation (MME 1) was shown in Figure 7. Absence of sharp endothermic peak at $126^{\circ} \mathrm{C}$, corresponding to the melting point of Amisulpride in DSC of formulation MME 1 indicate the absence of crystalline drug.

\section{Selection of Dose for Animal Studies}

The dose of amisulpride selected for intranasal administration was $1.2 \mathrm{mg} / \mathrm{kg}$ which was calculated based on the human dose using the formula,

$\mathrm{AED}=\mathrm{HED}^{\star}(\text { animal weight in } \mathrm{kg} / \text { human weight in } \mathrm{kg})^{-0.33}$

$\mathrm{AED}=$ animal equivalent dose in $\mathrm{mg} / \mathrm{kg}$.

$\mathrm{HED}=$ human equivalent dose in $\mathrm{mg} / \mathrm{kg}$.

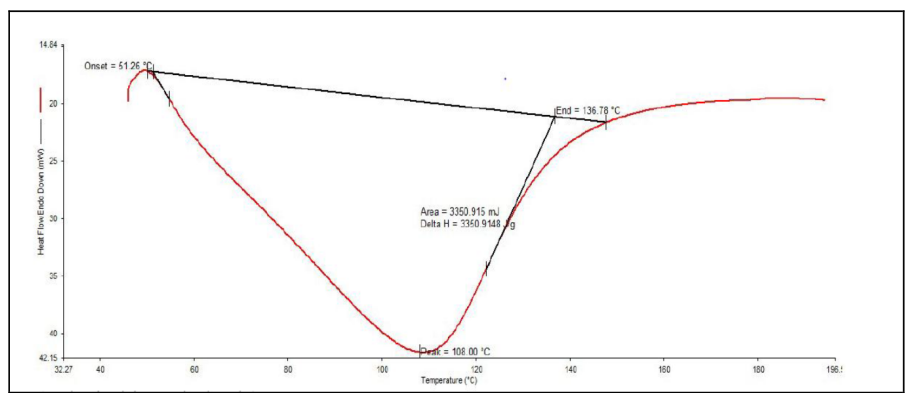

Figure 7: DSC thermogram of optimized MME 1 formulation. 


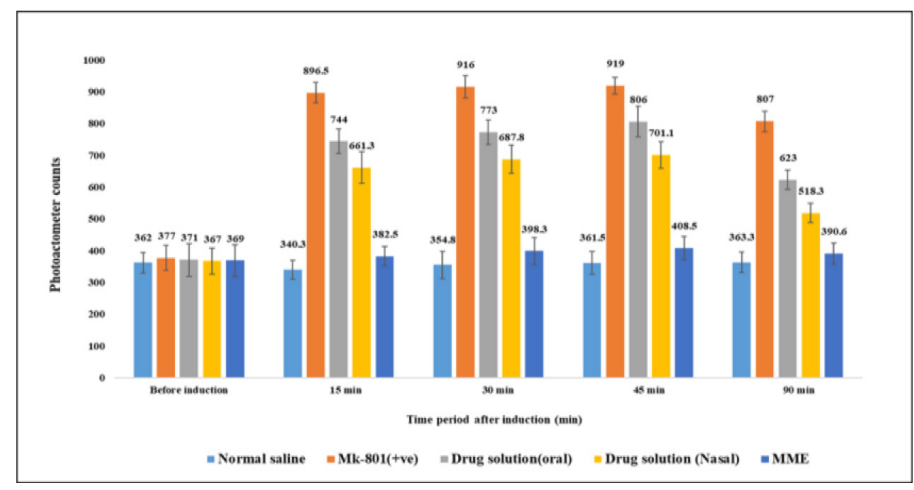

Figure 8: Locomotor activity in rats.

$($ mean $\pm S D ; n=6)$

\section{Pharmacodynamic Activity}

Locomotor activity was evaluated on psychosis induced rats using MK- 801 by photoactometer as described in section 2.10 . The photoactometer counts were Figure 8.

Photoactometer counts decreased by $93.85 \%$ in nasal MME1 treated group, $65.07 \%$ in nasal drug solution treated group and $41.47 \%$ in oral drug solution treated group in comparison to positive control. The intranasal MME1 has showed significantly high efficiency $(p<0.001)$. Therefore we conclude that intranasal microemulsion administration could be potential benefit compared to oral route.

\section{CONCLUSION}

In the present study we could develop mucoadhesive microemulsion of amisulpride for intranasal administration successfully. Ex vivo permeation of MME and ME formulations was significantly higher than drug solution. The antipsychotic activity of MME was significantly high compared to nasal drug solution and oral drug solution. Nasal drug solution also showed significantly high activity compared to oral drug solution. Therefore we conclude that intranasal microemulsion administration could be potential benefit compared to oral route.

\section{ACKNOWLEDGEMENT}

We acknowledge UCPSc, Kakatiya University, Warangal, Telangana, India, for providing all the facilities to perform the experimental work.

\section{CONFLICT OF INTEREST}

All the authors declare that they have no conflict of interest.

\section{REFERENCES}

1. Shivpal S, Jeetendra N, Rohit B, Vandana N, Nikhil K, VinayT, et al. Development and evaluation of orodispersible sustained release formulation of Amisulpridecyclodextrin inclusion complex. J Incl Phenom Macroycl Chem. 2014;78:239-47.

2. Indian pharmacopeia 2018 edition (8 ${ }^{\text {th }}$ edition). 2018;1.

3. Ghori MU, Mahdi MH, Smith AM, Conway BR. Nasal drug delivery systems: An overview. Am J Pharmacol Sci. 2015:3(5):110-9.

4. Hanson LR, Frey WH. Intranasal delivery bypasses the blood-brain barrier to target therapeutic agents to the central nervous system and treat neurodegenerative disease. BMC Neuro Sci. 2008;9(S3):S5.

5. Vyas TK, Shahiwala A, Marathe S, Misra A. Intranasal drug delivery for brain targeting. Curr Drug Deliv. 2005;2(2):165-75.

6. Chien YW, Chang SF. Intranasal drug delivery for systemic medications. Critical Reviews in Therapeutic Drug Carrier Systems. 1987;4(2):67-194.
7. Chein YW, Su KSE, Chang SF. Anatomy and physiology of the nose: Nasal systemic drug delivery; Drugs and pharmaceutical science, Marcel Dekker, New York. 1989;39:1-19

8. Illum L. Animal models for nasal delivery. J Drug Target. 1996;3:427-42.

9. Aboud HM, Komy El, Ali MH, EIMenshawe AA, AbdElbary SFA. Development, Optimization and Evaluation of carvedilol-Loaded Solid Lipid Nanoparticles for Intranasal Drug Delivery. AAPS Pharm Sci Tech. 2016;17(6):1353-65.

10. Huang $\mathrm{CH}$, Kimura R, Nassar RB, Hussain A. Mechanism of nasal absorption of drugs I: Physicochemical parameters influencing the rate of in situ nasal absorption of drugs in rats. J Pharm Sci. 1985;74(6):608-11.

11. Jaiswal $P L$, Darekar $A B$, Saudagar RB. A recent review on nasal microemulsion for the treatment of cns disorder. Int J Curr Pharma Res. 2017;9(4):5-13.

12. Omar S, Refai H, ElTahir K. Carbamazepine Mucoadhesive Nanoemulgel (MNEG) as targeting delivery system via the olfactory mucosa. Drug Delivery. 2012;19(1):58-67.

13. Acharya SP, Pundarikakshudu K, Panchal A, Lalwani A. Development of carbamazepine transnasal microemulsion for treatment of epilepsy. Drug Deliv Trans Res. 2013;3(3):252-9.

14. Casettari L, Illum L. Chitosan in nasal delivery systems for therapeutics drugs Journal of Controlled Release. 2014;190:189-200.

15. Kumar M, Pathak K, Misra A. Formulation and characterization of Nano emulsion-based drug delivery system of risperidone. Drug Dev Int Pharm. 2009;35(4):387-95.

16. Levy MY, Schutze W, Fuhrer C, Benita S. Characterization of diazepam submicron emulsion interface: Role of oleic acid. Journal of Microencapsulation. 1994;11(1):79-92.

17. Sharma G, Mishra AK, Mishra P. Intranasal cabergoline: Pharmacokinetic and pharmacodynamic studies. AAPS Pharm Sci Tech. 2009;10(4):1321.

18. Anilgoud K, Anjali DN. Development and evaluation of Zotepine loaded mucoadhesive microemulsion for intranasal delivery. JDDT. 2019;9(4-s):54-8.

19. Srividya R, Krishnaveni J. Brain targeting of chitosan-based diazepam mucoadhesive microemulsions via nasal route: Formulation optimization, characterization, pharmacokinetic and pharmacodynamic evaluation. Drug Development and Industrial Pharmacy. 2019;45(1):147-58.

20. Acharya SP, Pundarikakshudu K, Panchal A, Lalwani A. Development of phenytoin intranasal microemulsion for treatment of epilepsy. J Pharm Invest. 2015;45(4):375-84.

21. Patel MR, Patel RB, Bhatt KK, Patel BG, Gaikwad RV. Paliperidone microemulsion for nose-to-brain targeted drug delivery system: Pharmacodynamic and pharmacokinetic evaluation. Drug Deliv. 2016;23(1):346-54.

22. Aranaz I, Mengibar M, Harris R. Functional characterization of chitin and chitosan. Curr Chem Biol. 2009;3(2):203-30.

23. Illum L. Chitosan and its use as a pharmaceutical excipient. Pharm Res.1998;15 (9):1326-31.

24. Mandal S, DasMandal S. Design and development of Carbamazepine mucoadhesive microemulsion for intranasal delivery: An ex-vivo study. Int J Pharma Sci Rev Res. 2010;3:56-60.

25. Caramella C, Ferrari F, Bonferoni MC, Rossi S, Sandri G. Chitosan and its derivatives as drug penetration enhancer. Journal of Drug Delivery Science and Technology. 2010;20(1):5-13.

26. Aboofazeli R, Barlow DJ, Lawrence MJ. Particle size analysis of concentrated phospholipid microemulsions: Total light scattering. AAPS Pharm Sci. 2000;2(3):449-70

27. Patel RB, Patel MR, Bhatt KK, Patel BG. Formulation consideration and characterization of microemulsion drug delivery system for transnasal administration of carbamazepine. Bulletin of Faculty of Pharmacy, Cairo University. Faculty of Pharmacy, Cairo University. 2013;51(2):243-53.

28. Kumar M, Mittal KL. Handbook of microemulsion: Science and technology. New York, Basel: Marcel Dekker.1999;250-5

29. Ravisankar P, Devala RG. Novel RP-HPLC method for the determination of Amisulpride in pure and pharmaceutical formulations. J Chem Pharm Res. 2015;7(6):815-24.

30. Nicholas A, Peppas, Daniel A. carr. Impact of absorption and transport on intelligent therapeutics and nanoscale delivery of protein therapeutic agents. Chem Eng Sci. 2009;64(22):4553-65.

31. Ravi K, Krishnaveni J. Development and evaluation intranasal mucoadhesive in situ gels for brain targeting. JDDT. 2019;9(2-s):198-207.

32. Kumar M, Misra A, Babbar AK, Mishra AK, Mishra P, Pathak K. Intranasal nano emulsion-based brain targeting drug delivery system of risperidone. Int $\mathrm{J}$ Pharm. 2008;358(1-2):285-91.

33. Patel RB, Patel RM, Bhatt KK, Bharat G, Patel GB, Gaikwad RV. Microemulsionbased drug delivery system for transnasal delivery of Carbamazepine: Preliminary brain-targeting study. Drug Deliv. 2016;23(1):207-13.

Article History: Submission Date : 03-04-2020; Revised Date : 13-05-2020; Acceptance Date : 02-06-2020.

Cite this article: Ganta AT, Velupula R, Janapareddi K. Formulation and Characterization of Amisulpride Microemulsions for Brain Targeting Via Intranasal Route-pharmacodynamic Evaluation in Rat Model. J Young Pharm. 2020;12(2)Suppl:s25-s31. 